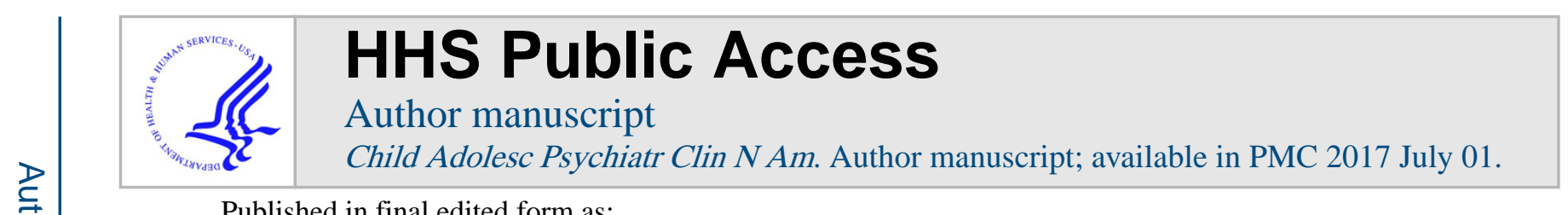

Published in final edited form as:

Child Adolesc Psychiatr Clin N Am. 2016 July ; 25(3): 473-487. doi:10.1016/j.chc.2016.03.002.

\title{
Opioid Use Disorders
}

Bikash Sharma, MD ${ }^{1}$, Ann Bruner, MD ${ }^{1,2}$, Gabrielle Barnett, MA ${ }^{1}$, and Marc Fishman, MD ${ }^{1,3}$ ${ }^{1}$ Mountain Manor Treatment Center, Baltimore MD

2Dept of Pediatrics, Johns Hopkins University, Baltimore MD

${ }^{3}$ Dept of Psychiatry, Johns Hopkins University, Baltimore MD

\section{Abstract}

Opioid use and addiction in adolescents and young adults, including heroin and non-medical use of prescription opioids, is a serious and growing health problem of epidemic proportions. Opioid use has devastating consequences for youth and their families, including: progression to full addiction, severe psychosocial impairment, HCV and HIV transmission with injection use, exacerbation of co-occurring psychiatric disorders, overdose, and death. This chapter will provide an overview of opioid use disorders (OUDs) in youth, including: etiologic factors, epidemiology, consequences, clinical presentation and course, assessment and diagnosis, overdose, detoxification, and treatment. Opioid overdose is a life-threatening emergency. Respiratory depression should be treated with naloxone, and respiratory support if necessary. Overdose should always be utilized as an opportunity to initiate addiction treatment. Opioid withdrawal management (detoxification) is often a necessary, but never sufficient, component of treatment for OUDs. Medications used in the treatment of withdrawal may include buprenorphine, clonidine and others for relief of symptoms. Treatment for OUDs is effective but treatment capacity is alarmingly limited and under-developed. Although there is a limited evidence base for youth specific treatment, emerging consensus supports the incorporation of relapse prevention medications such as buprenorphine and extended release naltrexone into comprehensive psychosocial treatment including counseling and family involvement.

\section{Keywords}

opioids; opioid use disorder; heroin; injection; prescription opioids; withdrawal; overdose

\section{Introduction / Background}

The current epidemic of opioid use disorders (both diverted prescription opioids and heroin) in adolescents and young adults is a growing problem with devastating consequences for youth and their families. Progression from initiation to full addiction is common, and often

Corresponding Author: Marc Fishman MD, 3800 Frederick Ave, Baltimore MD 21229, 410233 1400, 4102331666 (fax), mjfishman@comcast.net.

Publisher's Disclaimer: This is a PDF file of an unedited manuscript that has been accepted for publication. As a service to our customers we are providing this early version of the manuscript. The manuscript will undergo copyediting, typesetting, and review of the resulting proof before it is published in its final citable form. Please note that during the production process errors may be discovered which could affect the content, and all legal disclaimers that apply to the journal pertain. 
accelerated compared to other substances. Severe psychosocial impairment includes criminal justice involvement, school dropout, unemployment, and co-occurring psychiatric disorders. Medical morbidity includes the wellknown sequelae of injection drug use including $\mathrm{HCV}$, HIV, injection site infections, and others. Worst of all is the catastrophic mortality associated with overdose, and nearly every community in the country has now unfortunately experienced this tragic loss of life in a young person with an opioid use disorder (OUD).

The term "opioids" encompasses a class of a large number of drugs, both natural alkaloid compounds derived directly from the resin of the opium poppy (termed "opiates," including morphine and heroin) as well as related synthetic compounds (including oxycodone and hydromorphone.) All members of the opioid drug class share common pharmacological features as agonists of the mu opioid receptor. Opioids are highly addictive, with rapid progression to physiological dependence with tolerance and withdrawal. There is growing evidence to suggest a relationship between increased non-medical use of prescription opioids and heroin use in the US ${ }^{\mathrm{i}}$, and a significant proportion of adolescents who start with prescription opioids go on to injection heroin use $\mathrm{e}^{\mathrm{ii}} \mathrm{The}$ progression of use often follows a pattern that maximizes drug bioavailabilty and effect: oral prescription opioids to inhaled prescription opioids to inhaled heroin to injection heroin. Inhalation can encompass either smoking (heating heroin in foil and inhaling the smoke) and nasal snorting (of the powdered heroin); whether a patient smokes or snorts appears to be mostly influenced by peers and regional variations, but neither method is as potent or efficient as injection, which maximizes bioavailability. This phenomenon is more prominent in adolescent than adult opioid users $^{\text {iii }}$,and accelerates more quickly with an earlier age of first opioid use. This progression is also related to heroin's lower cost and higher potency, because tolerance to opioids builds up rapidly in adolescents and prescription opiates become prohibitively expensive with increased requirements for amounts of opioids as addiction advances ${ }^{\mathrm{iv}}$.

\section{Etiologic Factors}

Though our understanding remains limited, we do have increasing knowledge of the multiple factors involved in the etiology of opioid use disorders as a particular class of substance use disorders (SUD). OUDs share many features in common with addiction as a general process and with other SUDs, but there are a number of features that are specific to OUDs that may interact to influence vulnerability, progression and course. These factors range over several domains, including pharmacology, genetics, environmental influences, developmental influences, and comorbidities.

Opioids are all enormously reinforcing, one feature of their specific pharmacological properties. Positive reinforcement is largely mediated by the indirect downstream activation of dopamine receptors, one of the main final common pathways of reward. Though opioids produce somewhat less immediate dopamine release than stimulants, they rank very high in the hierarchy of rewarding substances and produce higher levels of positive reinforcement in animal and human self-administration models than almost all substances other than stimulants., as a feature of the intrinsic properties of the opioid receptor. Also very prominent and perhaps even more clinically significant in chronic OUDs is the typical negative reinforcement produced by opioid withdrawal once physiological dependence has 
occurred. Although the onset of withdrawal following opioid discontinuation varies with the half-life of the particular opioid, it produces a characteristic physiological syndrome with even brief abstinence or even delay of dosing. Steady exposure to opioids can produce this process of neuroadaptation leading to physiological dependence and withdrawal within as little as 4-8 weeks in opioid-naïve individuals, and much faster with reinstatement after relapse in those with prior dependence. Opioid withdrawal includes activation of the locus ceruleus region of the brain with increased systemic sympathetic tone, leading to its characteristic features (including chills, diarrhea, nausea, cramps, anxiety, etc; see below), accompanied by very high intensity cravings.

Approximately $40-60 \%$ of the vulnerability to any addiction is attributable to genetic factors $^{\mathrm{v}, \mathrm{vi}, \mathrm{vii}}$. Broad population twin studies ${ }^{\text {viii }}$ generally suggest that genetic factors have the strongest influence as a common vulnerability to SUDs in general rather than to phenotypic expression of vulnerability to or preference for any specific individual substance. On the other hand, with more advanced genetic techniques, several specific loci have been associated specifically with opioid use and OUD, with moderate opioid-specific heritable vulnerability. Specific allelic variants have been identified that seem to confer risk, in various genes including those coding for dopamine receptors and the dopamine transporter, opioid receptors, opioid neuropeptides, serotonin receptors and the serotonin transporter, and cannabinoid receptors. ${ }^{\text {ix,x }}$ For example, polymorphisms in the gene for the $m u$-opioid receptor (OPRM1) have been variably linked to differences in binding affinity and signaling efficiency, increased basal cortisol levels and opioid-mediated dynamic cortisol response, differential analgesic effects of morphine; and some studies have found associations between these allelic variations and rates of opioid dependence, though others have not. ${ }^{\mathrm{X}}$

As with genetic factors, environmental factors have strong influence as common factors increasing vulnerability broadly to SUDs. Typical risk factors such as stress, adversity, exposure to substance use in family and peers, etc. tend to increase risk for all substances rather than to opioid use or preference specifically. But, in addition, there are certainly unique environmental influences that differentially increase the risk of OUDs specifically. Such influences include: exposure to opioids as a specific class of substance, most importantly non-medical use; exposure to medical opioid analgesics; use of opioids by family, peers and other influential role models; permissive attitudes toward opioid use by influential role models; and access to opioids as a specific substance class.

Access is a particularly important environmental risk factor. The issue of ease of access, both for prescription opioids and for heroin, has been important in the genesis of the current epidemic. With increasing trends in medical prescribing of opioid analgesics over the past two decades, the overall US supply of prescription opioids has expanded greatly, with nonmedical diversion an unintended (but perhaps predictable) consequence. From 1999 to 2010 the per capita kilogram sales of prescribed opioid analgesics quadrupled. This trend parallels the concurrent curves of increasing per capita opioid treatment admissions and per capita opioid overdose deaths ${ }^{\mathrm{xi}}$. And while large increases in prescribing of opioid analgesics have mostly been a phenomenon of adult medical practice, the trend has emerged to a lesser extent in pediatric practice as well ${ }^{x i i}$ Heroin access has been promoted by increasingly 
plentiful and cheaper supplies. As with all substances, youth are particularly price sensitive in their substance use behaviors, often more so than adults. xiii, xiv

While prescription opioid use has a 10-fold greater prevalence than heroin among youth, it also fuels heroin use as a gateway of entry. Although the cost of prescription opioids on the street remains very high ${ }^{\mathrm{xv}}$,the cost of heroin has declined ${ }^{\mathrm{xvi}}$ and its purity has increased dramatically in recent years ${ }^{\mathrm{xvii}}$.This makes heroin a more economical alternative to prescription opioids, based both on price and potency ("cheaper and better"), once opioid addiction has become established.

Increasing purity has also promoted heroin use among youth in another way. Four decades ago, the low purity of available heroin meant that injection use was required to produce meaningful intoxication, and the need for injection has always been a major barrier to initiation of heroin use for youth. But over the past 2-3 decades as heroin purity in street supplies has increased, often exceeding $60 \%$ purity, nasal use or smoking is now a very efficient route of administration, and a young person can initiate and become addicted to heroin without injection use. Once heroin addiction is established, presumably, the hurdle to injection is less of a barrier ${ }^{\mathrm{xviii}}$.

More recently, efforts to limit the supply of prescription opioids have started to succeed, through various means, including medical education about opioid analgesic prescribing, law enforcement interdiction of "pill mills", use of prescription drug monitoring plans, and others. But as the availability of prescription opioids decreases and the street price of pills goes up, there is concern that there may be a corresponding shift toward heroin use. It is hoped that the trend toward less prescription opioid availability will help bring down both initial use of opioids and therefore overall rates of opioid use disorder, but it is also possible that more adolescents may start using heroin earlier after having initiated opioids through prescription opioids, or even using heroin as their first opioid. xix

Developmental vulnerabilities and comorbid psychiatric disorders are additional factors that confer considerable risk for all SUDs. Examples include problems with affective regulation, depression, anxiety, excitement-seeking, extreme extroversion, impulsivity, cognitive impairment, and problems with executive control. As far as we know, like the common environmental and genetic vulnerability factors shared by all SUDs, these tend mostly to increase risk for all substances rather than for opioid use or preference specifically. Both cooccurring psychiatric disorders and deviation from normal developmental trajectory seem to worsen with increasing severity and chronicity of overall SUD, and vice versa, with reciprocal worsening of course. For some, if unchecked, this progression may lead to opioid addiction. In this context OUDs may be seen as a more advanced stage of a general progression of SUD along a continuum. Some have hypothesized that there may be an inexact dose response relationship for some of these shared factors, making OUDs more likely with increased cumulative risk burden as a higher severity form of the more general disorder. 


\section{Epidemiology}

The non medical use of opioids in the general population is a growing public health and social concern across the entire lifespan ${ }^{\mathrm{i}}$.In the US, the number of people age 12 and older using prescription opioids more than doubled between 1975 and 2008 from $3.5 \%$ to over $9 \%{ }^{\mathrm{ii}}$ while the prevalence of marijuana and alcohol abuse decreased or plateaued ${ }^{\mathrm{iii}}$.In 2009 , 2.2 million Americans aged 12 years or older used prescription opioids as their first illicit drug, second only to marijuana ${ }^{\mathrm{xx}}$. In 2013 there were 169,000 persons aged 12 or older who used heroin for the first time (Figure 1). ${ }^{\mathrm{xxi}}$

Age

The involvement of youth in the current opioid epidemic is increasing, with alarming impact. In 2011, 8.7\% of 12th graders used prescription opioids illegally during the past year ${ }^{x x i i}$.Another study estimated $13 \%$ of high school seniors have a lifetime prevalence of nonmedical use of prescription opioids ${ }^{x x i i i}$.In 2009 approximately 250,000 US high school students (1.2\%) reported having used heroin at least once, and 77,000 Americans aged 18-20 reported using heroin in the past year, up from 56,000 in $2008^{x x i v}$. Across the lifespan, the group with the highest prevalence of both prescription opioid and heroin use, as well as the greatest increases in heroin use, is young adults ages18-25. While the number of users is increasing, the age of first use is decreasing ${ }^{\mathrm{xxv}}$. In 2013, 12.5\% of new illegal drug users began with prescription opioids ${ }^{\mathrm{xxvi}}$.Although the most recent SAMHSA report (2014-2015) shows some encouraging evidence that the rate of prescription opioid use among youths may be declining ${ }^{\mathrm{xxvii}}$, other studies have found that more adolescents are starting heroin use at a much younger age ${ }^{\mathrm{xxviii}}$.

Age of onset of opioid use is an important clinical epidemiological indicator and a robust marker of risk and clinical severity. Age of first use is correlated with the lifetime risk of OUD $^{\mathrm{xxix}, \mathrm{xxx}}$, and earlier age of onset of opioid use is associated with a higher prevalence of dependence, increasing clinical severity, and worsening consequences. Adolescents who are primarily abusing opioids have an earlier age of onset of any substance use compared to those who are currently using marijuana or alcohol (avg age 11.7 vs.12.6) ${ }^{\mathrm{xxxi}}$.The age of onset of opioid use for those who have opioids as their first illicit drug is much earlier

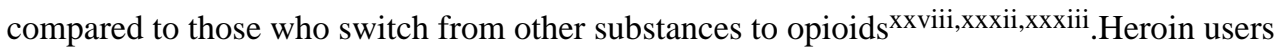
have first substance use much earlier than those who use non-heroin opioids ${ }^{\text {xxxiv }}$.Adolescents with earlier onset of prescription opioid or heroin use also have a more rapid progression from non-injection to injection heroin use $e^{\mathrm{xvi}, \mathrm{xxxiii}, \mathrm{xxxv}, \mathrm{xxxvi}}$. The strongest predictor for progression to regular heroin use is earlier initial heroin use, while age of initial use of any opioid, and age of regular use of other substances drugs (alcohol, marijuana) are also strong risk factors ${ }^{\mathrm{xxxvii}}$.

\section{Gender and race}

Contrary to the popular historic misconception of America's heroin problem being restricted to minorities and the disadvantaged inner city, youth opioid dependence, especially prescription opioid dependence, is a problem of a much broader demographic, including suburbia and higher socio-economic groups. The prevalence of opioid addiction is highest in 
white males ${ }^{x x x v i i i}$.The socio-economic status of youth initiating opioid use has increased over time. More male than female adolescents enter treatment for heroin use, but compared to other SUDs the representation of females among treatment seeking youth is much closer to even with males. ${ }^{x v i, x x x i, x x x v i}$ Among females seeking treatment for SUDs, there is a higher rate of heroin as their primary substance of use compared to male adolescents ${ }^{\mathrm{xxxix}}$.Female adolescents with heroin addiction are more likely to prefer injection use than male adolescents ${ }^{\mathrm{xl}}$ and are also more likely to initiate injection heroin use at a relatively younger age compared to males In fact, female adolescents often initiate injection heroin use within a year from their first illicit drug use, a faster rate of progression to injection use than male adolescents ${ }^{x l i}$. Possible explanations include influence of a romantic partner (often an older male IV drug user,) having a history of victimization/ ongoing victimization, gender specific personality traits and a rapid development of tolerance to opioids.

\section{Injection use}

Injection heroin use is the more advanced and usually later stage of OUD. Typically, inhaled (smoked or snorted) heroin is a precursor to injection heroin use ${ }^{x l i i}$.There are varying estimates of the proportion of adolescents with any form of opioid addiction who transition to injection heroin use, ranging from 40-90\% ${ }^{\mathrm{ii}, \mathrm{xxxv}}$ Almost $70 \%$ of young heroin users (age 18-25) eventually transition from nasal to injection heroin ${ }^{x l i i i}$,and almost half of adolescents with current heroin addiction are injection heroin users ${ }^{x v i i i, x l i v}$. Among patients seeking treatment for heroin addiction, the percentage of injection heroin use is even higher

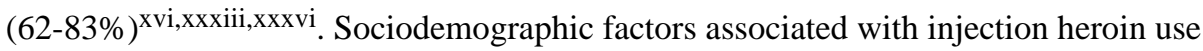
include poverty or unemployment, homelessness ${ }^{x l v}$, and history of childhood adversities $^{\text {xlvi, xlvii,xlviii,xlix }}$.

\section{Morbidity and mortality}

Morbidity and mortality related to opioid use have also escalated: in 2013 there were 16,000 deaths from prescription opioids, a 2.5-fold increase since 2001, and there were 8,000 deaths from heroin, a 5-fold increase over that same period. ${ }^{1}$ One hundred people die from a drug overdose every day in the US -- approximately one half of these are from prescription opioids and approximately one fifth from heroin And drug overdoses have surpassed motor vehicle crashes as the country's leading accidental cause of death. ${ }^{\text {li }}$ Prescription opioids account for nearly three out of four prescription drug overdoses, and the mortality as a result of it has surpassed all other forms of drug poisoning death in the US ${ }^{\text {lii,liii. From 2004-2008 }}$ more than half of all drug related medical emergencies and emergency department (ED) visits were due to heroin and opiates and during the same period ED visits involving the nonmedical use of opioids more than doubled ${ }^{\text {liv }}$. Opioids are one of the most common drugs used in suicide attempts in recent years ${ }^{\mathrm{lv}}$. The prevalence of HCV in young opioid users is particularly worrisome: in an opioid treatment trial of $16-21$ year olds, $18 \%$ were $\mathrm{HCV}+$ at baseline despite only 1.5 years of opioid dependence, with an additional $5 \%$ seroconverted at 12 weeks ${ }^{\text {lvi }}$. 


\section{Clinical presentation and course}

Opioid use disorder in an adolescent presents in many ways: from falling grades and breaking curfew, to legal involvement, to the worst case scenario---near fatal or even fatal overdose. Death does not require dependence: too many families only learn of their child's opioid use when the coroner reports the cause of their child's death, and an adolescent can overdose the very first time they try opioids. One unusual feature of opioids is their ready availability -- an adolescent does not need to "know a drug dealer;" prescription opiates are easily found in medicine cabinets, on kitchen counters, and in handbags. An adolescent's opioid use may become known after some crisis like arrest, job loss or school expulsion. Most adolescents know about dependence and withdrawal but many falsely believe that prescription opiates are not addictive, often reasoning that a doctor would never prescribe an addictive drug. And among heroin users, there is the myth that only IV heroin is addictive and nasal/smoked heroin is "safe." Adolescents who think they are using opioids "recreationally" are surprised when they experience withdrawal symptoms, and may attribute their opiate withdrawal symptoms to stress, viral illness, or food poisoning. Families may discover their adolescent is opioid dependent when he/she loses access to opioids (being broke, being locked up, or even going on vacation) and goes into withdrawal.

Adolescents can progress from first use to full blown dependence in months with a course of use that is often shorter than in adults. In general, the development of opioid dependence mirrors other drug dependencies, and possible warnings signs may include changes in peer group; decreasing involvement in social/leisure activities; isolation from family/old friends; mood changes such as irritability, depression, anger, and increased frequency of negative behaviors like truancy, lying, running away, stealing, and trouble with the police. As with other SUDs, tolerance develops and the adolescent needs escalating opioid doses, which increases the risk of overdose and death because there is less tolerance to respiratory depression.

Addiction to opioids can be conceptualized as the most complex and advanced stage of substance use disorder ${ }^{\mathrm{xxx}}$, $\mathrm{xxxvii}$ with the most severe health and social consequences. Adolescents with OUDs generally have higher severity of impairment than those with nonopioid SUDs, including larger amount of substances used, greater number of days of substance use, greater extent of polysubstance use, greater psychopathology and higher rates of co-occurring psychiatric disorders, higher rates of lifetime victimization, and higher rates

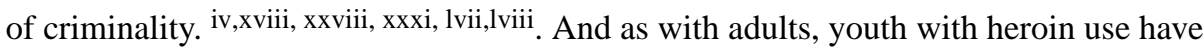
higher severity than those with prescription opioid use only, including higher rates of high school dropout; more severe psychiatric symptoms including higher rates of depression, suicide attempts, and more history of psychiatric treatment/hospitalizations; more concurrent cocaine use, and more risky sexual behaviors, prostitution and indiscriminate sex with strangers ${ }^{\mathrm{ii}}$ Mirroring their rapid development of dependence, adolescents and young adults with opioid addiction often have a more rapid deterioration in life circumstances, which in turn presents extreme barriers to treatment engagement and recovery, entrapping them in a vicious spiral of worsening addiction severity ${ }^{\mathrm{xxv}}$. 


\section{Assessment and diagnosis}

A complete assessment for an opioid use disorder requires a thorough medical and social history, in particular gathering information on: education, vocation, family, mental health, living arrangements/family structure and support, social service agency or legal involvement, peers, sex, and use of other drugs. As with other SUDs, opioid use disorder in DSM-V is a diagnosis across a continuum from mild to severe according to the number of diagnostic criteria met. For opioids, withdrawal and cravings are more prominent compared to other substances. Family history of SUD should look both for family members' past use and how any current use reflects family attitudes and the availability of opioids. The youth's living situation needs careful review of supervision (or the lack of it) and access to opioids (e.g., does the adolescent stay on weekends with grandmother who is prescribed pain medications.) There are also high rates of co-occurring mental health disorders, and patients should have a psychiatric assessment, with mood disorders, ADHD, and conduct disorder commonly seen. Patients with psychiatric illness and addiction are sometimes refused medications until they "get clean" but concurrent treatment of substance abuse and mental health disorders is more effective than trying to treat these conditions serially ${ }^{\text {lix }}$. High-risk sexual behaviors with STIs and pregnancy are common, as is amenorrhea due to the dopaminergic effects of opioids.

Urine drug screens are an essential component of assessment. Most street opioids (heroin, short acting prescription opioids, crushed long acting prescription opioid formulations which then are transformed to short acting) are detectable in urine for 2-3 days after use. While urine drugs screens are important, they are not sufficient to diagnose OUDs. Patients can time their use, adulterate the specimen, or substitute someone else's urine. It is important to note that certain specific opioids, such as buprenorphine, methadone or oxycodone, are not detected on many routine drug screens.

Patients describe euphoria, and feeling relaxed and mellow with mild to moderate intoxication - while on exam they can be substantially sedated. With higher doses patients become even drowsier ("nodding") and have increasing cognitive impairment. Pupillary constriction is a hallmark sign of opioid intoxication. Itching (from mast-cell histamine release), nausea, constipation, depression, urinary hesitancy, and sexual dysfunction are all common features of opioid use. Signs of injection use may include thrombosed veins ("track marks"), injection site erythema, bruises, abscesses or cellulitis, or scarring. An adolescent may try to hide visible injection sites with clothing (such as long sleeve shirts.)

\section{Overdose}

Coma, pinpoint pupils, and respiratory depression are the classic triad for opiate overdose. Eventually respiratory depression can lead to full respiratory arrest and death. Youth with OUD are especially vulnerable to overdose in the context of loss of tolerance following an interruption of opioid use. When they resume use with either a brief lapse or a full relapse, it is easy to miscalculate and use doses that were previously tolerated and seem familiar, but produce overdose due to loss of tolerance. Unfortunately one such vulnerable time is after detoxification, treatment, or other periods of abstinence or partial abstinence, unless patients are protected by relapse prevention medications (see below). It may be that youth are even 
more vulnerable to this phenomenon than adults because they are less experienced with drugs and developmentally they are more impulsive and have poor judgment.

Opioid intoxication/ overdose should be considered in any emergency in which a young person presents with decreased level of consciousness or obtundation. Many adolescents use multiple drugs, and in an acute/emergent setting blood/urine toxicology screens for other substances including blood alcohol concentration or breathalyzer should be obtained. In addition, drug use including opioids should be considered in any adolescent involved in a motor vehicle crash or other trauma.

\section{Withdrawal}

Opiate withdrawal is biphasic: an acute phase with marked somatic symptoms and then protracted abstinence with persistent but less severe somatic symptoms accompanied by prominent cravings. Acute withdrawal is not life-threatening but it is extremely uncomfortable, and adolescents who try to quit on their own ("cold turkey") usually resume use because they cannot tolerate withdrawal. The half-life of the drug used (for example 4-6 hours for heroin or 1-2 days for methadone) determines the timing of symptom onset. Without the usual exogenous opioids, the opiate receptor is not activated which causes a rebound increase in CNS activity. Signs and symptoms of opiate withdrawal include tachycardia, hypertension, mild fever, sweats, rhinorrhea, sneezing, pupillary dilation, anorexia, nausea, vomiting, diarrhea, piloerection, restlessness, irritability, yawning and insomnia. Patients report severe cravings during acute withdrawal. There are a variety of standardized withdrawal assessment tools such as the Clinical Opioid Withdrawal Scale (COWS) to quantify and track withdrawal severity ${ }^{1 x}$. Even after acute withdrawal, patients can have ongoing or recurrent complaints (such as malaise, restlessness, insomnia, sweats, anxiety, and irritability). In addition, cravings can persist and the intensity/frequency of the cravings fluctuates, often elicited or intensified by exposure to triggering cues, either external ("people, places, and things"), or internal ("HALT: being Hungry, Angry, Lonely or Tired".)

\section{Treatment}

There are multiple challenges facing youth with OUDs and their families. Patient engagement is difficult - treatment has to be developmentally appropriate, youth-friendly, and ideally have family involvement. Nationwide, treatment resources for adolescents are scarce, and insurance coverage and other funding varies widely. Outside of major metropolitan areas, there is often limited treatment availability, and what treatment is available may not be affordable. From 2010-2013 only $10.9 \%$ of those aged 12 or older who needed substance use disorder treatment received treatment at a specialty facility. Unfortunately less than half of patients who felt that they needed help actually made an effort to get treatment. ${ }^{1 x i}$ Among adolescent opioid users, from 1998-2008 there was a 10 fold increase in admissions to publically funded drug treatment centers for prescription opioid use disorders ${ }^{1 x i i}$,but despite this increase, treatment capacity is woefully limited. Detoxification alone is insufficient. The ASAM Criteria for adolescents recommends medically-monitored inpatient/residential treatment for adolescents needing pharmacologic 
management for detoxification, followed by intensive outpatient services that slowly taper in frequency and intensity, followed by longitudinal outpatient maintenance and monitoring. There is an increasing treatment role for the medical community given the frequency of comorbid psychiatric disorders, and the increasing knowledge of the benefits of relapse prevention medications. These highly specialized resources are even more limited.

Many people with OUDs are convinced they don't need help and can quit on their own. Youth are even more vulnerable to this idea; developmentally they may believe they are invincible and therefore they don't need treatment or medications or any help at all. The first step in treatment is just showing up, and in order to engage youth, treatment programs have to be interesting, relevant and friendly. The involvement of caring and supportive family/ adults is important, and treatment programs need to help families understand what and how much leverage they have and how to best use their influence.

\section{Detoxification (withdrawal management)}

Acute opiate withdrawal can be successfully managed with opioid agonists, alpha-2 agonists, nonsteroidal anti-inflammatories, anticholinergics, and antacids. Insomnia and agitation/anxiety should be aggressively managed with agents such as hydroxyzine, diphenhydramine, trazodone, clonidine or benzodiazepines. Care should be taken when using benzodiazepines in that many patients have often abused them and benzodiazepines are very reinforcing. While the alpha-agonist clonidine was long used as the primary detox medication, newer opioid agonists (such as buprenorphine) are now more routinely used since they are physiologically directed towards the opiate receptor and therefore more effective in alleviating symptoms of acute withdrawal. Buprenorphine, a high affinity partial mu agonist, can be tapered over a period of days or transitioned to a maintenance dose for relapse prevention for medication assisted recovery. Buprenorphine can be used alone but more preferably in combination with naloxone which has poor oral bioavailabilty; when the combination product is given sublingually there is minimal absorption of naloxone, but if diverted and used intravenously the naloxone is bioeffective. Because buprenorphine will displace other opioids, the first dose should not be given until the adolescent has moderate withdrawal symptoms to avoid the possibility of precipitated withdrawal.

\section{Emergency treatment of overdose}

In an acute overdose setting, patients may need emergency resuscitation including respiratory support. If opiate intoxication/overdose is suspected, the best immediate response is administration of the opiate antagonist naloxone (Narcan). Naloxone can be administered by multiple routes: intramuscular, intravenous, nasal, subcutaneous or endotracheal. Naloxone displaces bound opioids from opiate receptors, which reverses the overdose but may precipitate opiate withdrawal. Multiple and/or ongoing naloxone doses may be needed depending on the dose and half-life of the opioid. In response to the national epidemic of opiate abuse, many communities are providing/prescribing naloxone overdose kits to first responders, addicts, and addicts' families, along with appropriate training in an attempt to decrease the number of opiate overdoses and deaths. 


\section{Relapse Prevention Medications}

Although there is relatively little information about the use and effectiveness of pharmacotherapies for opioid dependence in adolescents (as opposed to adults where they are the clear standard of care),relapse prevention medications are nevertheless gaining more widespread adoption. Without relapse prevention medications, drop out and relapse among youth with OUDs have been the rule, with worse treatment outcomes than non-opioid youth SUDs. ${ }^{\text {xxxvi }}$ Methadone is not easily available for patients under the age of 18 , but can be considered when planning aftercare for young adults. Buprenorphine/Naloxone (Bup/Nal) maintenance as a relapse prevention medication has shown promising results in maintaining longer periods of abstinence from opioids, reducing treatment drop-out and reducing overdose. ${ }^{\text {lxiii,lxiv }}$ Another relapse prevention medication for opioid dependence is extended release naltrexone (XR-NTX) which can reduce opioid relapse, improve treatment adherence (including therapy/counseling) and decrease overdose in opioid users, ${ }^{\mathrm{xv}}$ and shows initial promising results in opioid dependent adolescents and young adults ${ }^{\text {lvii }}$. Many adolescents on extended Bup/Nal or XR-NTX treatment still continue to use other non-opioid drugs, relapse on opioids when they discontinue medications, have higher attrition rates compared to older patients, and remain at high risk for overdose, particularly when they drop out of treatment. ${ }^{\text {lxvi,lxvii }}$ Which of these medications is best for which patient is not yet wellunderstood, but emerging evidence suggests that outcomes are better with medications integrated into comprehensive psycho-social treatment.

\section{Clinical cases}

\section{Case 1}

$\mathrm{SM}$ is a 17yo white male who lives with his parents and two younger siblings in a rural town. He was an A/B student in high school where he played on the varsity team. He began binge drinking and smoking cannabis at parties at age 15, and by 17 was using substances most weekends. During his junior year he broke his ankle, requiring surgery and internal fixation. He was prescribed opioid analgesics peri-operatively, continued to have pain and was given repeated prescriptions. Two months post-op, he started escalating his use, taking higher doses at shorter frequencies. He started crushing the pills and snorting them. As he ran out of his prescriptions, he took opioids he found at home in the medicine cabinet and then started stealing supplies from friends and neighbors. He progressed to sniffing or smoking heroin when it was difficult to get pills, stealing money from his parents. He became irritable and reclusive, and was failing two classes. He tried to stop on multiple occasions, but would get sick, and was afraid to tell anyone. When confronted by his parents about the missing money, he broke down and asked for their help. His parents were devastated - they had never known a "drug addict" - and brought him to a substance abuse treatment center. During a 3-week inpatient stay, he underwent detoxification and received injectable extended release naltrexone (XR-NTX). He subsequently attended an intensive outpatient program (IOP), where he initially did well but briefly relapsed 6 weeks later after he declined a second dose of XR-NTX and missed sessions of treatment, thinking he could "do it on my own." He came back for a brief inpatient treatment episode to restart XR-NTX. He continued in IOP, then stepped down to less intensive outpatient treatment, including 
monthly doses of XR-NTX with parental monitoring. He has remained abstinent from opioids for 13 months.

\section{Case 2}

$\mathrm{KB}$ is a 16 yo WF from a suburban area. She was raised by her grandmother after her mother died of a heroin overdose. Her 21 yo brother is in a methadone treatment program. At age 11 she started using marijuana and cutting school; she has failed seventh grade twice. She smokes 1 pack of cigarettes/day, smokes marijuana daily, and has abused cough syrup, stimulant medications, benzodiazepines, and prescription opiates. Last year she started seeing a 23 yo man who introduced her to heroin, first nasal then injection. She is absent from her grandmother's house regularly, from overnight to days at a time. She has been on probation for CDS charges, but did not follow through with court mandated treatment. Her grandmother has had her emergently psychiatrically hospitalized for "out of control" behaviors. EMS was called to her school because she was unresponsive; she was resuscitated with naloxone. She spent the night in an emergency room and was transferred to inpatient substance treatment. She reported daily injection heroin use. Her labs showed UDS positive for marijuana and opiates, mildly elevated LFTs and HCV+. She was initially detoxed with buprenorphine and then transitioned to ongoing buprenorphine/naloxone as a relapse prevention medication. She was also started on an antidepressant. At grandmother's request, juvenile services placed her in a group home with a GPS electronic monitor. She attends intensive outpatient treatment at a dual diagnosis program where her buprenorphine/ naloxone is provided through observed administration several days per week.

\section{References}

i. Pradip, et al. Associations of Nonmedical Pain Reliever Use and Initiation of Heroin Use in the US. Center for behavioral Health Statistics and Quality Data Review. SAMHSA; 2013.

ii. Subramaniam GA, Stitzer MA. Clinical characteristics of treatment-seeking prescription opioid vs. heroin-using adolescents with opioid use disorder. Drug and Alcohol Dependence. Apr.2009 101:13-19. [PubMed: 19081205]

iii. Subramaniam GA, Stitzer MA, Woody G, Fishman MJ, Kolodner K. Clinical Characteristics of Treatment Seeking Adolescents with Opioid versus Cannabis/Alcohol Use Disorders. Drug Alcohol Depend. Jan 1; 2009 99(1-3):141-149. [PubMed: 18818027]

iv. Mills KL, Teesson M, Darke S, Ross J, et al. Young people with heroin dependence: Findings from the Australian Treatment Outcome Study (ATOS). Journal of Substance Abuse Treatment. 2004; 27:67-73. [PubMed: 15223096]

v. Uhl GR, Grow RW. The burden of complex genetics in brain disorders. Arch Gen Psychiatry. Mar; 2004 61(3):223-9. [PubMed: 14993109]

vi. Merikangas KR, Stolar M, Stevens DE, Goulet J, et al. Familial transmission of substance use disorders. Arch Gen Psychiatry. 1998; 55(11):973-979. [PubMed: 9819065]

vii. Tsuang MT, Lyons MJ, Meyer JM, Doyle T, et al. Co-occurrence of abuse of different drugs in men: the role of drug-specific and shared vulnerabilities. Arch Gen Psychiatry. 1998; 55(11): 967-97. [PubMed: 9819064]

viii. Kendler KS, Jacobson KC, Prescott CA, Neale MC. Specificity of genetic and environmental risk factors for use and abuse/dependence of cannabis, cocaine, hallucinogens, sedatives, stimulants, and opiates in male twins. Am J Psychiatry. Apr; 2003 160(4):687-95. [PubMed: 12668357]

ix. Nelson EC, Agrawal A, Heath AC, Bogdan R, et al. Evidence of CNIH3 involvement in opioid dependence. Mol Psychiatry. Aug 4.2015 
x. Kreek MJ, Levran O, Reed B, Schlussman SD, et al. Opiate addiction and cocaine addiction: underlying molecular neurobiology and genetics. J Clin Invest. Oct; 2012 122(10):3387-93. [PubMed: 23023708]

xi. Volkow ND, Frieden TR, Hyde PS, Cha SS. Medication-assisted therapies--tackling the opioidoverdose epidemic. N Engl J Med. May 29; 2014 370(22):2063-6. [PubMed: 24758595]

xii. Fortuna RJ, Robbins BW, Caiola E, Joynt M, et al. Prescribing of Controlled Medications to Adolescents and Young Adults in the United States. Pediatrics. 2010; 126:1108-1116. [PubMed: 21115581]

xiii. Anderson P, et al. Effectiveness and cost-effectiveness of policies and programmes to reduce the harm caused by alcohol. The Lancet. 2009; 373:2234-2246.

xiv. Chaloupka F, et al. Effectiveness of tax and price policies in tobacco control. Tobacco Control. 2011; 20:235-238. [PubMed: 21115556]

xv. Kuehn BM. Medication helps make therapy work for teens addicted to prescription opioids. Medical News and Perspectives. 2010; 303:2343-2345.

xvi. Gordon SM, Mulvaney F, Rowan A. Characteristics of adolescents in residential treatment for heroin dependence. The American Journal of Drug and Alcohol Abuse. 2004; 30:593-603. [PubMed: 15540495]

xvii. Werb D, Kerr T, Nosyk B, Strathdee S, et al. The temporal relationship between drug supply indicators: an audit of international government surveillance systems. BMJ Open. Sep 30.2013 3(9) BMJ Open.

xviii. Hopfer CJ, Khuri E, Crowley TJ, Hooks S. Adolescent heroin use: A review of the descriptive and treatment literature. Journal of Substance Abuse and Treatment. 2002; 23:231-237.

xix. National Institute on Drug Abuse. Prescription Opioid and Heroin Abuse. Apr 29. 2014 Presented by Nora D. Volkow, M.D.House Committee on Energy and Commerce Subcommittee on Oversight and Investigationshttp://www.drugabuse.gov/about-nida/legislative-activities/ testimony-to-congress/2015/prescription-opioid-heroin-abuse

xx. Johnston, LD.; O’Malley, PM.; Bachman, JG.; Schulenberg, JE. Vol. 1: Secondary School Students. Institute for Social Research, The University of Michigan; Ann Arbor, Michigan, USA: 2011. Monitoring The Future National Survey Results On Drug Use, 1975-2010.

xxi. Substance Abuse and Mental Health Services Administration. Results from the 2013 National Survey on Drug Use and Health: Summary of National Findings. Substance Abuse and Mental Health Services. Administration; Rockville, MD: 2014. NSDUH Series H-48, HHS Publication No. (SMA) 14-4863

xxii. McCabe SE, West BT, Boyd CJ. Motives for medical misuse of prescription opioids among adolescents. J Pain. Oct; 2013 14(10):1208-16. [PubMed: 23954519]

xxiii. McCabe SE, West BT, Teter CJ, Boyd CJ. Medical and nonmedical use of prescription opioids among high school seniors in the United States. Arch Pediatr Adolesc Med. published online ahead of print May 7, 2012.

xxiv. Johnston, LD.; O’Malley, PM.; Bachman, JG.; Schulenberg, JE. Vol. 1: Secondary School Students. Institute for Social Research, The University of Michigan; Ann Arbor, Michigan, USA: 2011. Monitoring The Future National Survey Results On Drug Use, 1975-2010.

xxv. Substance Abuse and Mental Health Services Administration. The NSDUH report, State Estimates of Nonmedical Use of Prescription Pain Relievers. Jan 8. 2013 http:// archive.samhsa.gov/data/2k12/NSDUH115/sr115-nonmedical-use-pain-relievers.htm

xxvi. Substance Abuse and Mental Health Services Administration. Results from the 2006 national survey on drug use and health: national findings. SAMHSA; Rockville: 2007. http:// files.eric.ed.gov/fulltext/ED498206.pdf

xxvii. Substance Abuse and Mental Health Services Administration. Center for Behavioral Health Statistics and Quality. National Survey on Drug Use and Health. Table 1.18A - Nonmedical Use of Pain Relievers in Lifetime, Past Year, and Past Month, by Detailed Age Category: Numbers in Thousands. 2013 and 2014. 2013 and 2014 http://www.samhsa.gov/data/sites/default/files/ NSDUH-DetTabs2014/NSDUH-DetTabs2014.htm\#tab1-18b 
xxviii. Branson CE, Clemmey P, Harrell P, Subramaniam G, Fishman M. Polysubstance use and heroin relapse among adolescents following residential treatment. Journal of Child and Adolescent Substance Abuse. 2012; 21:204-221.

xxix. Chen CY, Storr CL, Anthony JC. Early-onset drug use and risk for drug dependence problems. Addict Behav. Mar; 2009 34(3):319-22. [PubMed: 19022584]

xxx. Windle M, Windle RC. Early onset problem behaviors and alcohol, tobacco, and other substance use disorders in young adulthood. Drug Alcohol Depend. Feb 1; 2012 121(1-2):152-8. [PubMed: 21925804]

xxxi. Subramaniam GA, Ives ML, Stitzer MA, Dennis ML. The added risk of opioid problem use among treatment-seeking youth with marijuana and/or alcohol problem use. Addiction. 2010; 105:686-698. [PubMed: 20403020]

xxxii. Barry D, Syed H, Smyth BP. The journey into injecting heroin use. Heroin Addiction and Related Clinical Problems. 2012; 14(3):89-100.

xxxiii. Chiang S, Chen S, Sun H, Chan H, Chen WJ. Heroin use among youths incarcerated for illicit drug use: Psychosocial environment, substance use history, psychiatric comorbidity, and route of administration. The American Journal on Addictions. 2006; 15:233-241. [PubMed: 16923670]

xxxiv. Hopfer CJ, Mikulich SK, Crowley TJ. Heroin use among adolescents in treatment for substance use disorders. Journal of the American Academy of Child and Adolescent Psychiatry. 2000; 39:1316-1323. [PubMed: 11026188]

xxxv. Fuller CM, Vlahov D, Ompad DC, Shah N, et al. High-risk behaviors associated with transition from illicit non-injection to injection drug use among adolescent and young adult drug users: A case-control study. Drug and Alcohol Dependence. 2002; 66:189-198. [PubMed: 11906806]

xxxvi. Clemmey P, Payne L, Fishman M. Clinical characteristics and treatment outcomes of adolescent heroin users. Journal of Psychoactive Drugs. 2004; 36:85-94. [PubMed: 15152712]

xxxvii. Woodcock EA, Lundahl LH, Stoltman JJ, Greenwald MK. Progression to regular heroin use: examination of patterns, predictors, and consequences. Addict Behav. Jun.2015 45:287-93. [PubMed: 25765913]

xxxviii. Goldsamt LA, Harocopos A, Kobrak P, Jost JJ, Clatts MC. Circumstances, pedagogy and rationales for injection initiation among new drug injectors. J Community Health. Jun; 2010 35(3):258-67. [PubMed: 20127155]

xxxix. Pugatch D, Strong LL, Has P, Patterson D, et al. Heroin use in adolescents and young adults admitted for drug detoxification. Journal of Substance Abuse. 2001; 13:337-346. [PubMed: 11693456]

xl. Eaves CS. Heroin use among female adolescents: The role of partner influence in path of initiation and route of administration. The American Journal of Drug and Alcohol Abuse. 2004; 30:21-38. [PubMed: 15083552]

xli. Doherty MC, Garfein RS, Monterroso E, Latkin C, et al. Gender differences in the initiation of injection drug use among young adults. Journal of Urban Health: Bulletin of the New York Academy of Medicine. 2000; 77:396-414. [PubMed: 10976613]

xlii. Canfield MC, Keller CE, Frydrych LM, Ashrafioun L, et al. Prescription opioid use among patients seeking treatment for opioid dependence. Journal of Addiction Medicine. 2010; 4:108113. [PubMed: 20543897]

xliii. Gandhi DH, Kavanagh GJ, Jaffe JH. Young heroin users in Baltimore: A qualitative study. The American Journal of Drug and Alcohol Abuse. 2006; 32:177-188. [PubMed: 16595322]

xliv. Substance Abuse and Mental Health Services Administration. Treatment Episode Data Set (TEDS). 1999 - 2009. National Admissions to Substance Abuse Treatment Services. Substance Abuse and Mental Health Services Administration; Rockville, MD: 2011. DASIS Series: S-56, HHS Publication No. (SMA) 11-4646http://wwwdasis.samhsa.gov/teds09/TEDS2k9NWeb.pdf

xlv. Goldsamt LA, Harocopos A, Kobrak P, Jost JJ, Clatts MC. Circumstances, pedagogy and rationales for injection initiation among new drug injectors. J Community Health. Jun; 2010 35(3):258-67. [PubMed: 20127155]

xlvi. Neaigus A, Miller M, Friedman SR, Hagen DL, et al. Potential risk factors for the transition to injecting among non-injecting heroin users: a comparison of former injectors and never injectors. Addiction. Jun; 2001 96(6):847-60. [PubMed: 11399216] 
xlvii. Neaigus A, Gyarmathy VA, Miller M, Frajzyngier VM, et al. Transitions to injecting drug use among noninjecting heroin users: social network influence and individual susceptibility. J Acquir Immune Defic Syndr. Apr 1; 2006 41(4):493-503. [PubMed: 16652059]

xlviii. Hadland SE, Werb D, Kerr T, Fu E, et al. Childhood sexual abuse and risk for initiating injection drug use: a prospective cohort study. Prev Med. Nov; 2012 55(5):500-4. [PubMed: 22954518]

xlix. Ompad DC, Ikeda RM, Shah N, Fuller CM, et al. Childhood sexual abuse and age at initiation of injection drug use. Am J Public Health. Apr; 2005 95(4):703-9. [PubMed: 15798133]

1. National Institute on Drug Abuse. Overdose Death Rates. http://www.drugabuse.gov/related-topics/ trends-statistics/overdose-death-rates

li. Centers for Disease Control and Prevention. Vital Signs: Overdoses of Prescription Opioid Pain Relievers-United States, 1999-2008. MMWR. 2011; 60:1-6. http://www.cdc.gov/vitalsigns/ PainkillerOverdoses/index.html.

lii. Centers for Disease Control and Prevention. Center for Surveillance, Epidemiology, and Laboratory Service. Increases in Heroin Overdose Deaths 28 States, 2010 to 2012. Centers for Disease Control and Prevention; Atlanta, GA: 2014. MMWR, 63(39):849-854

liii. Chen LH, Hedegaard H, Warner M. Drug-poisoning Deaths Involving Opioid Analgesics: United States, 1999-2011. NCHS Data Brief. Sep.2014 (166):1-8. [PubMed: 25228059]

liv. Substance Abuse and Mental Health Services Administration. Drug Abuse Warning Network report: trends in emergency visits involving nonmedical use of narcotic pain relievers. 2010. http:/www.samhsa.gov/data/sites/default/files/DAWN096/DAWN096/ SR096EDHighlights2010.htm

lv. Substance Abuse and Mental Health Services Administration. Drug Abuse Warning Network. 2011: National Estimates of Drug-Related Emergency Department Visits. Substance Abuse and Mental Health Services Administration; Rockville, MD: 2013. HHS Publication No. (SMA) 13-4760, DAWN Series D-39http://www.samhsa.gov/data/sites/default/files/DAWN2k11ED/ DAWN2k11ED/DAWN2k11ED.pdf

lvi. Subramaniam GA, Fishman MJ, Woody G. Treatment of opioid-dependent adolescents and young adults with buprenorphine. Curr Psychiatry Rep. Oct; 2009 11(5):360-3. [PubMed: 19785976]

lvii. Fishman MJ, Winstanley EL, Curran E, Garrett S, Subramaniam G. Treatment of opioid dependence in adolescents and young adults with extended release naltrexone: Preliminary caseseries and feasibility. Addiction. 2010; 105:1669-1676. [PubMed: 20626723]

lviii. Wu L, Woody GE, Yang C, Blazer DG. How do prescription opioid users differ from users of heroin or other drugs in psychopathology? Results from the National Epidemiological Survey on Alcohol and Related Conditions. Journal of Addiction Medicine. 2011; 5:28-35. [PubMed: 21532972]

lix. Riggs PD, Mikulich SK, Davies RD, et al. A randomized controlled trial of fluoxetine and cognitive behavioral therapy in adolescents with major depression, behavior problems, and substance use disorders. Arch Ped Adolesc Med. 2007; 161:1026-1034.

1x. Wesson DR, Ling W. The Clinical Opiate Withdrawal Scale (COWS). J Psychoactive Drugs. 2003; 35(2):253-9. https://www.drugabuse.gov/sites/default/files/files/ ClinicalOpiateWithdrawalScale.pdf. [PubMed: 12924748]

1xi. Substance Abuse and Mental Health Services Administration. Results from the 2013 National Survey on Drug Use and Health: Summary of National Findings. Substance Abuse and Mental Health Services Administration; Rockville, MD: 2014. NSDUH Series H-48, HHS Publication No. (SMA) 14-4863http://www.samhsa.gov/data/sites/default/files/ NSDUHresultsPDFWHTML2013/Web/NSDUHresults2013.htm

1xii. Substance Abuse and Mental Health Services Administration. Treatment Episode Data Set (TEDS): 1998-2008. State Admissions to Substance Abuse Treatment Services; Rockville, MD: 2010. Center for Behavioral Health Statistics and Quality. DASIS Series: S-55, HHS Publication No. (SMA) 10-4613http://wwwdasis.samhsa.gov/teds08/TEDS2k8Sweb.pdf

1xiii. Warden D, Subramaniam GA, Carmody T, Woody GE, et al. Predictors of attrition with buprenorphine/naloxone treatment in opioid dependent youth. Addict Behav. Sep; 2012 37(9): 1046-53. [PubMed: 22626890] 
1xiv. Woody GE, Poole SA, Subramaniam G, Dugosh K, et al. Extended vs short term buprenorphinenaloxone for treatment of opioid-addicted youth: a randomized trial. JAMA. 2008; 300:2003-20. [PubMed: 18984887]

lxv. Krupitsky E, Nunes EV, Ling W, Illeperuma A, et al. Injectable extended-release naltrexone for opioid dependence: a double-blind, placebo-controlled, multicentre randomised trial. Lancet. Apr 30; 2011 377(9776):1506-13. [PubMed: 21529928]

lxvi. Schuman-Olivier Z, Weiss RD, Hoeppner BB, Borodovsky J, et al. Emerging adult age status predicts poor buprenorphine treatment retention. J Subst Abuse Treat. Sep; 2014 47(3):202-12. [PubMed: 24953168]

lxvii. Dreifuss JA, Griffin ML, Frost K, Fitzmaurice GM, et al. Patient characteristics associated with buprenorphine/naloxone treatment outcome for prescription opioid dependence: Results from a multisite study. Drug Alcohol Depend. Jul 1; 2013 131(1-2):112-8. [PubMed: 23333292] 


\section{Key points}

- $\quad$ The current epidemic of opioid use and addiction in adolescents and young adults is worsening, including heroin and non-medical use of prescription opioids.

- Opioid use has devastating consequences for youth and their families, including: progression to full addiction, severe psychosocial impairment, $\mathrm{HCV}$ and HIV transmission with injection use, exacerbation of co-occurring psychiatric disorders, overdose, and death.

- $\quad$ Progression of opioid use disorders (OUDs) in youth often follows a characteristic pattern from use of diverted prescription opioid analgesics to sniffed or smoked heroin to injection heroin.

- Opioid overdose is a life-threatening emergency. Respiratory depression should be treated with naloxone, and respiratory support if necessary. Overdose should always be utilized as an opportunity to initiate addiction treatment.

- Opioid withdrawal management (detoxification) is often a necessary, but never sufficient, component of treatment for OUDs. Medications used in the treatment of withdrawal may include buprenorphine, clonidine and others for relief of symptoms.

- Treatment for OUDs is effective but treatment capacity is alarmingly limited and under-developed.

- Although there is a limited evidence base for youth specific treatment, emerging consensus supports the incorporation of relapse prevention medications such as buprenorphine and extended release naltrexone into comprehensive psychosocial treatment including counseling and family involvement. 


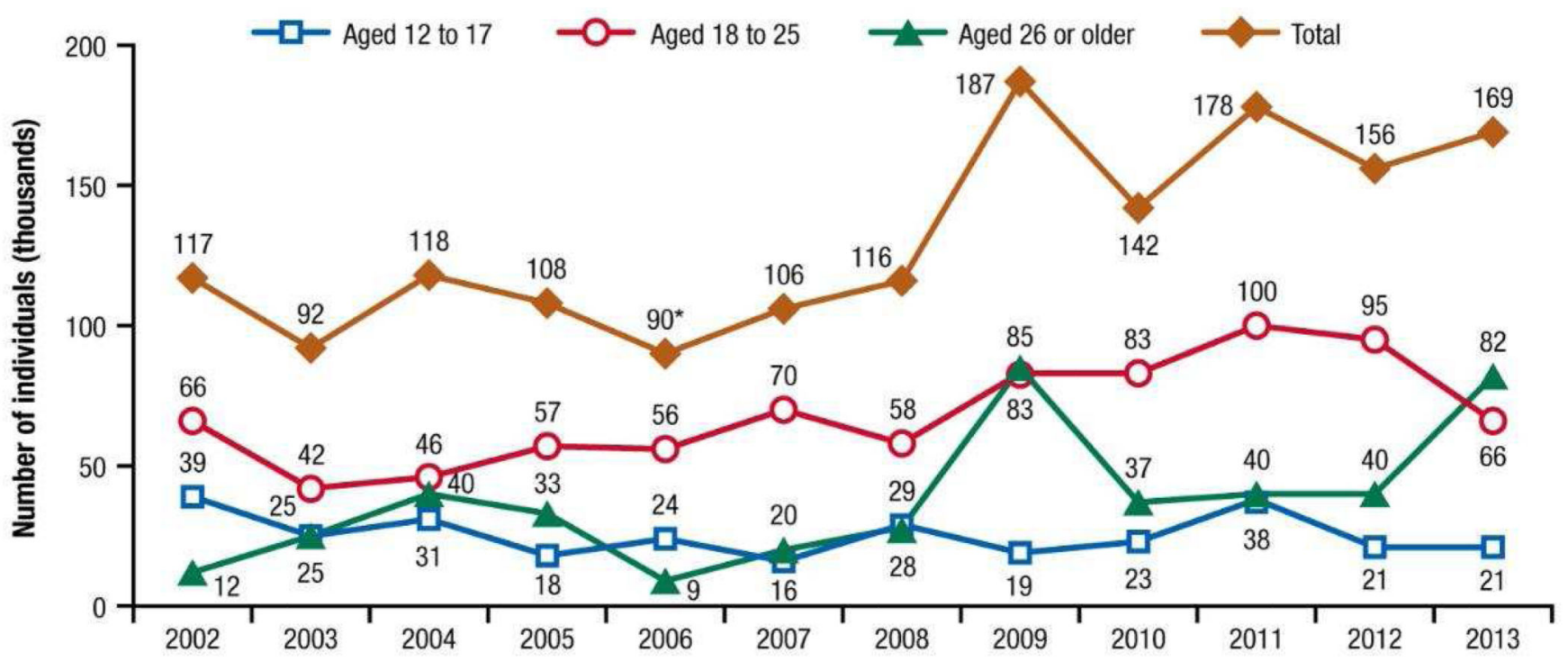

Figure 1. Past year initiation of heroin among individuals aged 12 or older, by age group: 2002 to 2013

From Lipari RN and Hughes A. The NSDUH Report: Trends in Heroin Use in the United States: 2002 to 2013. The CBHSQ Report: April 23, 2015. Substance Abuse and Mental Health Services Administration, Center for Behavioral Health Statistics and Quality. Rockville, MD; with permission. 